Viewpoint Article, RELC Journal 44 (2), 195-208, 2013

\title{
Displaying critical thinking in EFL academic writing: A discussion of Japanese to English contrastive rhetoric
}

\author{
Jim McKinley \\ Faculty of Liberal Arts, Sophia University, Japan
}

\begin{abstract}
This article provides an examination of the literature on issues surrounding the problems Japanese university students face in learning critical argument in their English academic writing courses. Japanese students' critical thinking skills are criticized as not fostered in their university education, perhaps due to Confucian education ideals, Japanese "readerresponsible" rhetorical structures, or misinterpretations by Western instructors. The article is presented in four sections providing first, an examination of English L2 in the Japanese context, second, an analysis of Japanese to English contrastive rhetoric, and third, a discussion of the debate on Japanese university students' critical thinking in EFL writing, and finishes with several suggestions to provide ways of dealing with the key challenges and foster more positive development of critical thinking in Japanese students' EFL academic writing.
\end{abstract}

\section{Keywords}

critical thinking, EFL writing, Japanese to English contrastive rhetoric, expanding circle

Corresponding author:

Jim McKinley, Faculty of Liberal Arts, Sophia University, Japan. Email: j-mckinl@sophia.ac.jp

\section{Introduction}

The debate on Japanese students' critical thinking skills involves claims by Western and Japanese researchers and academics ranging from scathing to heroic. In order to get to a clear idea of the issues Japanese university students face regarding the need to display critical thinking in their EFL writing, which I argue is crucial for students to successfully develop as academic English writers, I draw on literature from three areas. First, I offer three main issues as they pertain to English L2 in the Japanese context, including what it means for Japan to be an "expanding circle" country, how Japan's English education does not fit in to the BANA and TESEP contexts but rather the TiDC (Teaching in Difficult 
Circumstances) context, and finally Turner's (2011) argument against using Confucianism as an excuse for faulting EFL in Japan. Next, I discuss two areas of issues in Japanese to English contrastive rhetoric with particular focus on first, some criticisms of Japanese writing made several decades ago viewed later as over-generalized and second, influences of socio-cultural theory on our understanding of Japanese EFL writing. The final section provides a discussion of Japanese students' critical thinking skills in three parts: first, I highlight negative stereotypes; next I take a cultural perspective on defining critical thinking, return to the discussion on the impact of Confucian ideals on Japanese students' thinking, and highlight some successful Japanese EFL writing cases; and finally I return to the issues regarding Japanese to English contrastive rhetoric that may prevent students from successfully displaying critical thinking in their EFL writing, closing the section with a suggestion that gender should also be considered in this debate. The conclusion closes with some proposals for dealing with these issues and providing Japanese EFL students with better opportunities to successfully display critical thinking in their academic writing.

\section{English L2 in the Japanese Context}

In presenting the article in these particular sections, my intention in this first section is to show that the "inner circle" developments in English L2 writing education have not been considered carefully in Japan due to the rhetorical differences between Japanese and English, and that this may be the cause for the inconsistency of approaches currently taken in EFL writing education in Japan. To clarify, Japan is a country located in what Kachru (1992) described as the "expanding circle." This is the outermost of three concentric circles of English: the inner circle is comprised of the countries where English is the native language spoken, and where ESL is taught (US, UK, etc.); the outer circle includes countries where English is not the native language, yet it holds important historical value and has official status in certain arenas (India, The Philippines, Kenya, etc.); and the expanding circle, which includes most of the rest of the world where English has no official status but is still used widely, and where EFL is taught (most of Europe, East Asia, Egypt, etc.). 
Another significant distinction made in terms of the variety of practice of English education was made by Holliday (1994), using the acronyms BANA and TESEP to differentiate between the mainstream English language teaching discourse in native-English settings in Britain, Australasia, and North America (BANA) and the English language teaching discourse in educational settings at the Tertiary, Secondary and Primary (TESEP) levels throughout the world. Holliday raised the issue that there were considerable differences in the discourse and the often-difficult circumstances found in classrooms. An important discussion regarding this issue is the misapplication of such methodologies first described by West (1960) with his distinction of Teaching in Difficult Circumstances (TiDC). These distinctions made by West and Holliday emphasized the fact that the mainstream English language teaching methodologies were based on ESL taught in multilingual, intensive settings with a small number of students and trained, native-speaking teachers. Outside this context, ESL and EFL practices were used in very different circumstances. EFL was often taught in monolingual settings under the pressure of passing examinations, with less frequent class meetings, larger classes and uncertain teacher training or proficiency. The distinctions were made to encourage skepticism about monolithic Western methods and to urge researchers and teachers to consider alternatives to the belief that BANA products and ideas were the only options in English language teaching regardless of the context (Smith, 2010).

One final clarification to be made regarding the issue of contrasting varieties of practice in different cultures is that of the impact of Confucianism on English language education in East Asia. Turner discusses the dangers of Western hegemony in interpreting the impact as detrimental to East Asian students ability to learn English, and encourages researchers and teachers to take a more "globally neutral" approach (2011:109). She refers to Ballard and Clanchy (1991) who described Western academic cultures as "extending knowledge" and Confucian cultures (including Japanese) as "conserving knowledge." What this distinction implies is that Western cultures are inherently forward thinking, leaving Confucian cultures behind. Turner refers to Kubota's (1999) criticism of this distinction, labeling it "orientalist." The problem with this criticism, Turner points out, is that it suggests that the perspective is somehow universally accepted. Even in doing so, there is no reason to 
assume that a "conserving knowledge" approach should be seen as negative. Turner encourages those involved in this discussion to remember the importance of understanding the differences between the Confucian thinking in eastern educational approaches and the embedded critical thinking in Western critical approaches and not to place higher value of one over the other. This is particularly important with the increase of globalization in higher education. The issue of the Confucian influence on Japanese learners will be discussed further in the section on Japanese students' critical thinking.

\section{Japanese to English Contrastive Rhetoric}

The focus of this section is on the first of the five major reasons raised by Aspinall (2003) as to why EFL education has been unsuccessful in Japan-that there is a great linguistic disparity between Indo-European languages, such as English, and Japanese, which is, according to Aspinall (2003), an Altaic language ${ }^{1}$. An examination is done through an analysis of Japanese to English contrastive rhetoric, which will further highlight the challenges faced by Japanese students, particularly in displaying critical thinking when writing in English in a foreign language context. This section is organized in two parts. The first looks at some early over-generalized criticisms of Japanese writing describing it as "indirect" (with some explanation of the persistence of the grammar-translation method in language teaching in Japan) and "inductive" through use of the rhetorical pattern ki-shoten-ketsu (which arguably has practically disappeared from literature on Japanese writing). The second part discusses the influences of socio-cultural theory on more recent understanding of strongly maintained Japanese principles, reader versus writer responsibility, and genre-based EFL writing instruction.

In the findings of a self-initiated 1966 study, researcher Robert Kaplan initiated contrastive rhetoric research (Connor, 2008). Kaplan established the idea that students whose L1 grammatical and organizational structures differ greatly from those of their chosen L2 would find language acquisition more challenging. While reflecting on Asian learners of English, he remarked that, "Some Oriental writing...is marked by what may be called an approach by indirection" and portrays the "Oriental" writing style as a spiral (Kaplan,

\footnotetext{
${ }^{1}$ Although Aspinall claims Japanese to be an Altaic language, the official language family for Japanese has not been universally agreed upon; "macro-Altaic" may be a better description.
} 
1966:17). However, despite his having shed light on a major problem inherent in East Asian grammar-translation methodology, researchers of Japanese to English contrastive rhetoric such as Noor (2001) and Stapleton (2001) criticize Kaplan's 1966 findings for over-generalizing. Due to such criticism and further research into writing styles in Asian languages, in 1987 Kaplan revised his assessment of "Oriental" writing style to take a less critical stance of its structure.

Connor (2008) noted that some researchers have misinterpreted and fixated on Kaplan's article, maintaining contrastive rhetoric as "static", ignoring developments. Connor cites Kaplan's own 2000 and 2005 publications as examples of how contrastive rhetoric has continued to develop. In the following paragraphs I will highlight some of the issues long considered static aspects of Japanese to English contrastive rhetoric that have remained unchallenged.

Kaplan noted in his oft-criticized 1966 study about second language acquisition that the grammatical structures of many East Asian languages, including Japanese, differ greatly from those generally used in English. This reasoning lends itself to supporting the persistence of grammar-translation methodologies in Japanese L2 writing instruction, one of Aspinall's (2003) five reasons why English education is unsuccessful in Japan.

Some Japanese researchers of Japanese to English contrastive rhetoric have claimed that Japanese writing is characterized by its inductive style, i.e. not directly stating the thesis in the introduction, but rather hinting at it. The inductive style has been described as manifesting itself in the classical form of ki-shou-ten-ketsu (Hirose, 1998; Kubota, 1997; 1998), which forces readers to draw their own conclusions based on the information given, a characteristic known as "reader responsibility" (Kubota, 1997). Though most researchers agree on the quasi-inductive (Hinds, 1990) nature of ki-shou-ten-ketsu, no researcher has come up with an unchallengeable definition of the style (Kubota, 1997; Hirose, 2005).

The ten of the essay, sometimes referred to as a "topic shift," is what sets the Japanese writing style apart from the generally accepted English language essay format (Hinds, 1983), in which it may be recognized as opposing argument. In a Japanese essay, as proposed by Takemata (1976, cited by Hinds in 1983), a writer begins his or her argument 
in the ki portion of their composition, just as writers of essays in English would present their thesis statement at the beginning of an essay. When writing in English, the shou, or topical development phase, is represented through the presentation of commentary and evidence-generally known as body paragraphs-and occurs in alternation with ten-the transitional phase (Kubota, 1997). Both English and Japanese essays end with conclusions-the ketsu (Hinds, 1983). Hinds explained that in this type of Japanese writing "the main ideas do not appear until the end and that the paragraphs before the main ideas do not constitute the reasons or evidence for the main ideas" (Kubota, 1998:70). The type of inductive writing style described here goes against the generally preferred deductive writing style for native English speakers, which is characterized by providing the thesis in the introduction of a broad topic that is then supported or defended using evidence (Noor, 2001), but this is not the preference of only native English speakers. Kubota (1992) described one study that showed Japanese professors preferred expository and persuasive essays to be deductive, and that good Japanese essays share a similar writing structure to well written English essays (Kubota, 1997: 461).

According to researchers of socio-cultural theory (Lantolf \& Thorne, 2006), Japanese writers are influenced by strongly maintained principles (Atkinson, 2003; Casanave, 2002) such as aimai (ambiguity) and haragei, literally translated as "force of personality," as defined by Davies and Ikeno (2002). These ideas have played a large role in defining the way that many Japanese people act, speak and write. Similar to aimai, haragei is often used to avoid direct confrontation either verbal or written because it does not force the speaker to voice explicit, potentially offensive opinions and allows-if not forces-the target party to inductively draw its own conclusions based on the context of the situation. Hinds (1985) suggests that while writing in English often assigns the task of effectively conveying one's meaning to the writer, Japanese writers employ "reader-responsible rhetoric", which instead puts the task of finding meaning on the reader (Noor, 2001)-further evidence of aimai and haragei in Japanese writing. According to Kubota (1997; 1998), McCagg criticized this idea in 1996; after re-analyzing the content used in Hinds' 1987 study, he concluded, "Japanese texts do not generally require greater cognitive effort from readers 
for comprehension than English texts do, as long as the reader and the writer share the same cultural and linguistic knowledge" (Kubota, 1998:70).

Though consideration of socio-cultural theory in EFL and ESL teaching is relatively recent, this concept, introduced in the late 1990s, has helped academic theorists understand the intimate bond between L2 writers and their environment (Rinnert \& Kobayashi, 2001; Casanave, 2003). Due to the fact that many writers receive no formal writing instruction during their schooling (Casanave, 2002; Hirose, 2005), it becomes even more important to acknowledge this inherent connection, especially in a genre-based writing curriculum because with no formal instruction on writing forms, there is little or no basis on which to build students' understanding of the various writing genres. Hirose, in her 2005 study, concluded that students who are not educated in the guidelines of academic writing will, when asked to pen a composition, merely transcribe spoken, colloquial dialogue created either initially in Japanese and directly translated into English, strictly adhering to the grammar-translation method, or written conversationally in English. L2 students will often draw from their past experiences or the sample sentences provided to them while preparing for essay exams (Casanave, 2003). They will sometimes attempt to make their writing sound native by mimicking features from their sources (Masao, 1976) or copying the text directly (Casanave, 2002)-tendencies that often result in the inhibition or complete loss of writer voice and identity. Ivanič (1998) raises the questions:

What can be attributed to the author, what to the reader, and what to the community? Is copying from another writer a positive act, a way of showing agreement and allegiance? A way of taking to yourself the values, ideas and discourses of your discipline? Or is it a sin comparable to forgery, known as plagiarism? (p.4)

Such copying is noted when students use quotes instead of paraphrasing or summarizing, and have difficulty integrating those quotes. Students who successfully integrate source information may have done so by mimicking their sources.

\section{Japanese students' critical thinking}

In this final section, I offer a discussion of the ongoing debate on Japanese students' critical thinking. As the universal value of critical thinking is too difficult to ascertain, a specific 
context is significant. For students in Japan, I argue that the negative stereotypes of Japanese learners are often misinterpretations by Western instructors and researchers, but that the Western understanding of critical thinking is still beneficial to the learning process and should be strongly encouraged in ways that allow Japanese students to challenge ideas. Even if these students do not go on to study in Western universities overseas, having an understanding of both Eastern and Western perspectives of critical thinking will be a great advantage.

This section is organized as follows: first, some significant negative stereotypes are raised. I then provide a working definition of critical thinking in order to move into a discussion of possible misinterpretation of the impact of Confucian ideals on Japanese EFL writing, and I note some cases in which Japanese students successfully displayed critical thinking in their EFL writing. This is followed by a return to some of the issues raised in Japanese to English contrastive rhetoric such as non-linear progression, personal voice, and inductive style as potential hindrances to Japanese students' ability to display critical thinking in EFL writing; and finally, I offer the suggestion that gender may play a role in the debate.

Some researchers argue that Japanese students may not be able to write critically, citing traditions of collectivist and hierarchical traditions that inherently discourage students from developing a distinct identity or voice in their writing (Atkinson, 1997). Some academics such as Jane Barnes Mack-Cozzo, who taught English at universities in Japan for 12 years, go even further, emphasizing the idea that students are not only discouraged from writing explicitly but also are steered away from "creative original thinking... for it goes against the wa (harmony)" (Mack-Cozzo, 2002:47). However, other researchers (e.g. Stapleton, 2002; Kubota, 1999) vehemently argue against this stereotype, insisting that Japanese students take distinctly Japanese approaches to critical writing, and are therefore no less critical.

Bruce Davidson, a long-time academic in Japanese universities and researcher of Japanese students' critical thinking asserts, “Japan paradoxically offers both an encouraging and an inhibiting environment for the development of critical thinking skills" (Davidson, 1995, para.3). According to an American student enrolled at the University of Tokyo, "Students 
were afraid to ask questions. They were afraid someone might ridicule them for not knowing the answer" (Taylor, 1983 in Davidson, 1995, para.8). A Japanese graduate student of Davidson's studying in the UK reflected this sentiment and stated, "even Japanese educational system doesn't encourage us to have our own ideas" (Davidson, 1995, para.10). Davidson (1995) takes this argument a step further and states that based on his own in-class studies, "Many people in Japan seem to have some difficulty discussing ideas or even in explaining them" (para.7). He argues that many Japanese students find the act of discussing or critiquing ideas difficult because "they do not have any opinions; and if they have opinions, they often cannot explain or justify them" (Davidson, 1995, para.7), thus further promoting the idea that Japanese students have an inability to think critically.

The arguments of both Atkinson (2003) and Davidson (1995) directly contradict Stapleton's (2001) study in which he took writing samples (of responses to provocative essays he wrote) from 45 undergraduate students in courses with the title "English Writing" in order to propose a model of assessment for critical thinking. In this study Stapleton concludes that, "participants demonstrated a fundamental understanding that all opinions require support" (p.526) and wrote with "individualized voices, which are closely related to critical thinking ability" (p. 534). Furthermore, students who lack background knowledge about or some level of familiarity with their assigned topic are less likely to demonstrate the ability to think critically due to "a lack of shared assumptions between the non-Asian researchers and their Japanese students" (Stapleton, 2001:530).

It is important in reference to the argument about Japanese students' critical thinking to provide a working definition of critical thinking. I refer to Ennis's (1998) definition from his article Is Critical Thinking Culturally Biased? in which he explains "critical thinking is thinking that is reasonable and reflective, and is focused on what to believe or do" (p.16). He goes on to explain that critical thinking is not limited to individuals, and suggests that as long as "group thinking" exists, it can be done critically. With this understanding, the goal of critical thinking, either individual or collective, then is to make reasonable decisions by seeking reasons and alternatives. The importance of critical thinking is stressed differently in East Asian cultures where social practices focus on collective concordance and compliance (Atkinson, 2003). It has been suggested that this interpretation of an inability 
to think critically may be due to the structure of the Japanese education system (Lee-Cunin, 2005), which has maintained somewhat Confucian ideals that dictated the importance of the relationship between master and pupil and decreed that a student was never to question his or her master (Stapleton, 1995).

However, it may be that the impact of Confucian ideals has been misinterpreted by the West. Turner (2011) points out that as the number of students from East Asian countries such as China, Japan, Korea and Taiwan has increased in the UK, their behavior has served as a point of difference between Eastern and Western students. She argues that this difference has become entrenched, but that Western interpretations, maintaining the negative stereotypes of "passive" or "silent" or "uncritical" East Asian students, are no longer appropriate (p.97). Turner explains that Western instructors see the passive nature or silence of East Asian students in classrooms as resistance to speaking in class, but she argues that there are culturally weighted differences regarding both silence and listening, which are seen as proactive. While Western approaches may emphasize "learning through speaking," this is an activity traditionally frowned upon by East Asian students who would prefer to follow the tutor who should serve as an exemplar or model demonstrating what should be done. It is a different way of learning (opposite to the Western approach of tutor as facilitator), reflecting Confucian tradition in which students follow their tutor's lead on "their own individual journey of self-perfection" (Turner, 2011:161). Turner emphasizes the importance of recognizing and understanding both the conflict between, and transformative effects of these two approaches as intercultural interaction plays an increasingly significant role in the global cultural construction of international universities.

Turner (2011) goes on to explain how the "contrasting educational ideologies" of East and West place different value on critical thinking. Because "being critical is historically embedded in Western educational culture as a positive value," it requires an understanding of the "rhetoricity of being critical" (p.185). As East Asian students have not grown up with such rhetoricity, they may be seen in Western contexts as "uncritical." Traditionally it is important for a Japanese student in Japan to display an ability to listen and read without criticizing or evaluating, and rather than reinforcing opposition, to find harmony in a comparison of two opposing views. However, these actions are not in line with the goals of 
Western educational approaches. For such Japanese students, Turner explains that providing critique is more than "being critical," which may be understood as simply disagreeing (p.189). She emphasizes that being critical has "gone global as an educational issue" (p.192) and an understanding of "rhetorical exchange value" is of crucial importance, considering the strengths of both Eastern and Western interpretations of it, in order to avoid East Asian students seeing the Western understanding of being critical as superior.

Despite past claims that cultural tendencies keep students from developing distinct critical voices in their writing, evidence of students' critical thinking abilities is becoming increasingly visible (Stapleton, 2002; Kubota, 1999). These findings mirror those of Casanave's in her 2002 study. Here she reported that although the students of one particular ESL teacher sometimes encountered problems while attempting to complete the exercises they had been assigned, they also "wrote that they were learning to think critically" (Casanave, 2002:60). It would seem necessary that in order to write in a way that is acceptable to raters of English ability, one must first develop her or his critical thinking skills (Stapleton, 2002; Casanave, 2002) and a good understanding of the strategies required to meet raters' expectations. Yuko, another one of Casanave's test subjects, admitted that she had little background in her chosen topic of International Relations, and consequently had a hard time processing and understanding the materials she had been provided with for her final paper (Casanave, 2002).

The main issues in the debate on Japanese students' critical thinking are often based on particular characteristics inherent in the Japanese language. As explained in the previous section, Kaplan (1966) provided graphic depictions of various types of L1 writing styles and portrayed Japanese writing as a circular spiral of logic that spends the entirety of the essay alluding to a point but perhaps never explicitly stating it even by the end-a tendency that reflects the influence of aimai and haragei (Davies \& Ikeno, 2002)-what Hinds (1990) referred to as a "delayed introduction of purpose" (Dyer \& Friederich, 2002:278. Historically, instruction in Japanese L1 writing concentrated on personal expression, requiring students to write about their feelings and personal experiences. Along this line, students also practiced kansobun, in which writers describe their impressions of assigned readings (Hirose \& Sasaki, 1994). In Dyer and Friederich's 2002 
study on teaching autobiography in Japan, they cite Arai (2000), a Japanese professor of English in Tokyo, who in a criticism of the L1 writing process stated that "in Japanese writing instruction, the emphasis is placed on two elements, jiyu (freedom) and jibun no iken (one's own opinion): 'Students are encouraged to write down their ideas spontaneously, without worrying about such irrelevancies as organization, clarity, or logic'” (p. 6, cited in Dyer \& Friederich, 2002:278). This understanding of non-linear logic or random quality in Japanese essay writing is based on the history of essay writing. Indeed, the Japanese word for essay, zuihitsu, is translated as, "writing at random" (Dyer \& Friederich, 2002).

The idea that Japanese writing uses non-linear logic has prevailed in related publications over the decades. In Fox's (1994) book Listening to the World, she quoted a student in Japan on the vagueness of Japanese writing compared to English: "Japanese is more vague than English,' she [a Japanese student] tells me. 'It's supposed to be that way. You don't say what you mean right away. You don't criticize directly'" (Fox, 1994:8). However, this debate on non-linear logic in Japanese essay writing is concerned more with personal writing rather than expository writing. According to Dyer and Friederich (2002), Japanese personal writing is not all that different from English personal writing. Although university English composition instructors may believe that this aspect of Japanese writing is a handicap for Japanese students learning to write English academic essays, both Doi (2001) and Matsuda (2001) insist that this tendency should be viewed as a concept that enables Western theorists to develop a more comprehensive understanding of the Japanese individual and cultural psyche.

The issue of impersonal writing needs to be raised at this stage as a style Japanese student writers struggle with in expressing their thinking in their academic writing. In his article Opinions of identity in academic writing, Hyland (2002) raises the issue about the "myth of impersonality" in academic writing. He explains that teachers requiring students to remove personal writing, deleting phrases such as I think or I believe, is an oversimplification of the issue. He explains that the differences between disciplines affect the ways people in those disciplines argue and express themselves. As learning to write at university often means taking on new identities, he suggests students need to learn how subject-specific writing 
differs, in order to provide them with "an awareness of the options that academic writing offers" (Hyland, 2002:352).

The Japanese "habit" of writing inductively (Kubota, 1997) can also be attributed to the principle of kenkyo, which is literally defined as "modesty" (Davies \& Ikeno, 2002). Davies and Ikeno explain that kenkyo is important in Japanese culture because "Self assertiveness is more or less discouraged, while consideration for others is encouraged" (p. 143). This idea manifests itself in Japanese speech as well. While addressing an individual of a higher rank or social status than themselves, native Japanese speakers will add softeners to their speech or let their sentences trail off in order to avoid being perceived as overly assertive. This tendency may show itself in the writing of a Japanese student of English, particularly if he or she has not received formal instruction in writing academically (Hirose, 2005). Furthermore, Japanese mothers often emphasize to their children the importance of empathy and conformity, two characteristics that directly contradict the nature of critical thinking (Stapleton, 2001), and this tendency manifests itself in both the classroom and in students' writing. Davidson (1995) notes that his Japanese students were "often quick to drop a point they make in the face of disagreement. They will often immediately grant the validity of the opinion of the other party without challenging her reasoning" (Davidson, 1995, para.9). Thus, the notion of conformity, which is emphasized in Japanese society from a young age (see Yoshino's 1992 critique of the phenomenon of nihonjinron as cultural nationalism), may also impact on the level of argumentation and critical thinking in Japanese students' writing.

While socio-cultural tendencies and pre-formulated schemata often play a large role in the molding of an individual's writing style (Xiao, 2008), it is also important to consider the implications of gender when studying the development of a particular writing style or tendency (Kubota, 2003). This importance is especially emphasized in the Japanese language where male and female speaking styles are clearly differentiated. Japanese speakers universally accept and employ humble tones and softeners as a way to show their respect for elders and higher-ranking individuals - for women, this often includes their husband and other men in their lives. This demarcation of status is not only verbal but also written - the kanji for husband is comprised of shu (master) and jin (person), while the 
kanji for wife is sometimes written as $k a$ (home) and nai (inside). Since the Tokugawa Shogunate and subsequent rise of the very paternally focused Confucianism, women have been both demoted and subordinated (Davies \& Ikeno, 2002) despite the passing of equal rights laws and the introduction of co-educational higher institutions (McVeigh, 2002). This cultural subjugation, although rapidly changing, is reflected in the words of the Japanese language itself; by nurture and socialization, Japanese spoken by females uses more softeners and is consequently more indirect than Japanese spoken by males, which is often very concise (Davies \& Ikeno, 2002). Though briefly mentioned by Kubota (2003), whether gender actively plays a role in the ability of Japanese students of English to communicate both concisely and effectively should be investigated further, due to the fact that many of the studies cited in this article were performed on test groups consisting primarily of female subjects.

The debate on Japanese students' critical thinking is difficult to conclude. If Japanese students' critical thinking skills are not fostered in their university education, whether due to Confucian education ideals, Japanese "reader-responsible" rhetorical structures, or misinterpretations by Western instructors, this has serious implications regarding their ability to meet writing requirements in English-medium university studies overseas.

\section{Implications for Language Teachers}

Having considered a number of significant issues affecting Japanese students' ability to display critical thinking in their English academic writing, I now offer the following four suggestions:

1. Students would benefit from being taught the difference between personal, narrative writing, and objective, academic writing. Students should be encouraged to use "I" to make the claim (I argue) and should be allowed to choose or be provided with familiar topics.

2. Through training to understand that the starting point for Japanese students as writers may be a desire to use non-linear organization and to place emphasis on "freedom" and personal opinion, instructors can avoid unhelpful assessments of students' writing. With this understanding, instructors can provide students with some highly structured formulas that require students to assemble a strong claim and balanced, concisely stated and 
supported argument. Having students learn these constructs should allow them to more easily display linear logic and avoid an inductive development and the "reader-responsible" dilemma. This also helps to avoid the gender-related issue of any obligation female Japanese students may feel to be indirect.

3. Instructors should understand the importance of not fixating on a need to "disagree" in order to display critical thinking. This can help to avoid the misunderstanding that a student who seems to take a neutral stance is not automatically agreeing with an idea. Students need to be encouraged to find a way to frame an argument so they can make a natural claim about it. Instructors should avoid topics that require students to make ethical "right" or "wrong" choices.

4. Topic choices that encourage students to argue either in favor or against a particular aspect of the topic are very important. With experience in framing arguments to suit their needs, these students will later more easily navigate "agree or disagree" writing prompts. For example, rather than "English is now being taught at the elementary school level in Japan. Do you agree or disagree with this?" a better prompt would be, "English is now being taught at the elementary school level in Japan. Consider the following: Can elementary school English teachers in Japan deliver appropriate lessons? Could this present issues in Japanese language-particularly kanji-development? What advantages are there to

learning a foreign language at a young age? Choose one of these questions and develop your response.

\section{Conclusion}

It can be argued that Japanese university students studying EFL must learn to demonstrate and use their critical thinking abilities in order to write coherently and cohesively. However, effecting a drastic change to the EFL curriculum in Japan could take years (Poole, 2005) due to the structure and corporate nature of the Japanese university system. Furthermore, these changes not only have structural implications but also cultural ones. The Japanese principle of kenkyo may lead Western teachers and researchers to interpret Japanese students as having inhibited ability to develop an individual sense of voice and 
personality in their writing (see Matsuda, 2001, for discussion). While the teaching methodologies in many Japanese EFL classrooms have changed over the most recent decades, it is still necessary for both native and non-native instructors at the university level to have a basic understanding of the fundamentals that fuel Japanese culture (Stapleton, 2001) in order to teach their students more effectively.

Regardless of developments in globalization, the cultural issues described in this article remain strong in Japan. Although writing constructs such as ki-shou-ten-ketsu have practically disappeared from the discussions on Japanese academic writing, the quasiinductive style persists, leading Japanese EFL writers-even those with years of domestic and overseas exposure to English-to write vague thesis statements in the introduction, holding off until the conclusion to make any kind of real claim. When these students head overseas to English medium universities for exchange or postgraduate study, they suffer. Developments in EFL academic writing in Japan do not need to 'Westernize', but I argue these students would benefit greatly-and more obviously display Western ideas of critical thinking-from writing on carefully selected and dissected topics and learning the fundamental strategies of typical academic English essays including a strong thesis, topic sentences that match the content statement, and attributing sources to develop the thesis.

\section{References}

Aspinall RW (2003) Japanese nationalism and the reform of English language teaching. In: Goodman R and Phillips D (eds) Can the Japanese change their education system? Wallingford, CT: Symposium Books, pp.103-118.

Atkinson D (1997) A critical approach to critical thinking in TESOL. TESOL Quarterly 31(1): 71-94.

Atkinson D (2003) Writing and culture in the post-process era. Journal of Second Language Writing 12(1): 49-63.

Ballard B and Clanchy J (1991) Teaching students from overseas: A brief guide for lecturers and supervisors. Sydney, Australia: Longman Cheshire. 
Casanave CP (2002) Writing games: Multicultural case studies of academic literacy practices in higher education. Mahwah, NJ: Lawrence Erlbaum.

Casanave CP (2003) Looking ahead to more sociopolitically-oriented case study research in L2 writing scholarship. Journal of Second Language Writing 12: 85-102.

Connor U (2008) Mapping Multidimentional Aspects of Research: Reaching to Intercultural Rhetoric. In: Connor U, Nagelhout U and Rozycki W (eds) Contrastive Rhetoric: Reaching to Intercultural Rhetoric, Indiana: John Benjamins Publishing Company, pp. 299-315.

Davidson B (1995) Critical Thinking Education Faces the Challenge of Japan. Inquiry: Critical Thinking Across the Disciplines 14(3): 31 pars. Available at: http://www.shss.montclair.edu/ inquiry/spr95/davidson.html (accessed 16 May 2010).

Davies RJ and Ikeno O (2002) The Japanese Mind: Understanding Contemporary Japanese Culture. North Clarendon, VT: Tuttle Publishing.

Doi T (2001) The Anatomy of Dependence (special edition). Tokyo, Japan: Kodansha.

Dyer B and Friederich L (2002) The personal narrative as cultural artifact: Teaching autobiography in Japan. Written Communication 19(2): 265-296.

Ennis RH (1998) Is critical thinking culturally biased? Teaching Philosophy 21: 15-33.

Fox H (1994) Listening to the World: Cultural Issues in Academic Writing. Urbana, IL: National Council of Teachers of English.

Hinds J (1983) Contrastive Rhetoric: Japanese and English. Text 3(2): 183-195.

Hinds J (1985) Misinterpretations and common knowledge in Japanese. Journal of Pragmatics 9(1): 7-19.

Hinds J (1990) Inductive, deductive, quasi-inductive: Expository writing in Japanese, Korean, Chinese and Thai. In: Connor $U$ and Johns $A$ (eds) Coherence in writing: Research and pedagogical perspective. Alexandria, VA: TESOL, pp.87-110. 
Hirose $\mathrm{K}$ (1998) The effects of English paragraph writing instruction on Japanese university students. JACET Bulletin 29: 51-64.

Hirose K (2005) Product and process in the L1 and L2 writing of Japanese students of English. Hiroshima, Japan: Keisuisha.

Hirose K and Sasaki M (1994) Explanatory variables for Japanese students' expository writing in English: An exploratory study. Journal of Second Language Writing 3: 203-229.

Holliday AR (1994) Appropriate Methodology and Social Context. Cambridge, UK: Cambridge University Press.

Hyland K (2002) Options of identity in academic writing. ELT Journal 56(4): 351-358.

Ivanič R (1998) Writing and Identity: The Discoursal Construction of Identity in Academic Writing. Amsterdam, The Netherlands: Benjamins.

Kachru B (1992) World Englishes: Approaches, issues, and resources. Language Teaching 25: 114.

Kaplan RB (1966) Cultural thought patterns in inter-cultural education. Language Learning 16: 1-20.

Kaplan RB (1987) Cultural thought patterns revisited. In: Connor U and Kaplan RB (eds) Writing Across Languages: Analysis of L2 text. Reading, MA: Addison-Wesley, pp.9-21.

Kubota R (1992) Contrastive rhetoric of Japanese and English: A critical approach. PhD Thesis, University of Toronto, Canada.

Kubota R (1997) A reevaluation of the uniqueness of Japanese written discourse. Written Communication 14(4): 460-480.

Kubota R (1998) An investigation of L1-L2 transfer in writing among Japanese university students: Implications for contrastive rhetoric. Journal of Second Language Writing 7: 69-100.

Kubota R (1999) Japanese culture constructed by discourses: Implications for applied linguistics 
research and ELT. TESOL Quarterly 33(1): 9-35.

Kubota R (2003) New approaches to gender, class, and race in second language writing. Journal of Second Language Writing 12(1): 31-47.

Lantolf JP and Thorne SL (2006) Sociocultural Theory and the Genesis of Second Language Development. Oxford, UK: Oxford University Press.

Lee-Cunin M (2005) The Japanese Student Perspective on Universities. In: Eades JS, Goodman R and Hada Y (eds) The 'Big Bang' in Japanese Higher Education: The 2004 Reforms and the Dynamics of Change. Melbourne, Australia: Trans Pacific Press, pp.136-164.

Mack-Cozzo JB (2002) If you think we have problems... Japan's inferior university system. American Enterprise 13(6): 46-47.

Masao K (1976) The Japanese Language and Intercultural Communication. In: Tsutomu K (ed) The Silent Power: Japan's Identity and World Role. Tokyo, Japan: Simul, pp.51-73.

Matsuda PK (2001) Voice in Japanese written discourse Implications for second language writing. Journal of Second Language Writing 10: 35-53.

McCagg P (1996) If you can lead a horse to water, you don't have to make it drink: Some comments on reader and writer responsibilities. Multilingua 15(3): 239-256.

McVeigh BJ (2002) Japanese Higher Education as Myth. Armonk, NY: ME Sharpe.

Noor R (2001) Contrastive rhetoric in expository prose: Approaches and achievements. Journal of Pragmatics 33(2): 255-269.

Poole GS (2005) Reform of the university English language teaching curriculum in Japan: A case study. In Eades JS, Goodman R and Hada Y (eds) The 'Big Bang' in Japanese Higher Education: The 2004 Reforms and the Dynamics of Change. Melbourne, Australia: Trans Pacific Press, pp.242-273.

Rinnert C and Kobayashi H (2001) Differing perceptions of EFL writing among readers in Japan. The Modern Language Journal 85(ii): 189-209. 
Smith R (2010) Teaching English in Difficult Circumstances: A New Research Agenda [PowerPoint slides] Available at:

http://iatefl.britishcouncil.org/2010/sites/iatefl/files/session/documents/R._Smith__Teaching_in_Difficult_Circumstances_-_A_New_Research_Agenda_0.pdf (accessed 17 October 2011).

Stapleton P (1995) The Role of Confucianism in Japanese Education. The Language Teacher 19(4): 13-16.

Stapleton P (2001) Assessing Critical Thinking in the Writing of Japanese University Students: Insights About Assumptions and Content Familiarity. Written Communication 18(4): 506-548.

Stapleton P (2002) Critical thinking in Japanese L2 writing: Re-thinking tired constructs. ELT Journal 56(3): 250-257.

Turner J (2011) Language in the Academy: Cultural Reflexivity and Intercultural Dynamics. Bristol, UK: Multiligual Matters.

West M (1960) Teaching English in Difficult Circumstances. London, UK: Longmans, Green.

Xiao Y (2008) Building Formal Schemata with ESL Student Writers: Linking Schema Theory to Contrastive Rhetoric. Asian EFL Journal 32: 1-20.

Yoshino K (1992) Cultural Nationalism in Contemporary Japan: A Sociological Enquiry. New York: Routledge. 